\title{
On traction performance improvement for wheeled earth-moving machines
}

\author{
Vladimir Zhulay, Vitaliy Tyunin* and Denis Bobrov \\ Voronezh State Engineering University, 84, 20-letiya Oktyabrya St., Voronezh, 394006, Russia
}

\begin{abstract}
The article reviews the design of wheeled automotive equipment, consisting of doubled driving wheels of different diameters. It presents results obtained in experimental studies of this design, as well as conclusions based on the performed studies.
\end{abstract}

\section{Introduction}

Automotive equipment of earth-moving machines (such as bulldozers, motor graders, scrapers) serve not only for accommodation of loads and external forces, pressure transfer to the ground, movements over the work site and traveling in self-propelled mode to a new work site, but also for process purposes by providing the tractive effort to ensure the thrust force on the attachment during earth cutting and moving operations [1].

Earth-moving machines have automotive equipment of two types: wheel and track-mounted.

Wheeled machines have a number of advantages as compared with tracked ones, namely: higher endurance, higher travelling speed, reduction in metal consumption per structure, reduction of operation costs, etc. Moreover, in case of relocation wheeled equipment enables the machines to use public roads.

One of significant shortcomings of wheel-mounted automotive equipment is the impossibility of maximum utilization of the adhesion weight due to high contact stresses.

One of methods to increase the traction power of wheeled machines is to double driving pneumatic-tire wheels. Doubled wheels of the same size are known to be used on agricultural tractors $[2,3,4]$. Driving wheel doubling results in increased traction capacity of tractors, reduced specific fuel consumption and soil compaction. However, application of this method leads to increasing resistance to motion during transport operations.

There are certain designs of wheeled automotive equipment that incorporate additional wheel expanders $[5,6,7,8]$ to increase surface traction of automotive equipment, but they are bulky and difficult to manufacture and operate.

\section{Methods}

It is proposed to preserve positive properties, obtained by doubling driving wheels and the lack of negative factors, by means of an additional driving wheel of a smaller diameter, as shown in Fig. 1.

\footnotetext{
* Corresponding author: tuninvl@yandex.ru
} 
The additional wheel of an earth-moving machine will not contact the solid bearing surface, therefore the rolling resistance will not increase and the additional wheel will not be subject to wear.

While moving on a deforming bearing surface (Fig. 2), the primary driving wheel will "dig in", and the bearing surface will be contacted by the additional wheel. In this case, the tractive effort of the earth-moving machine will increase.

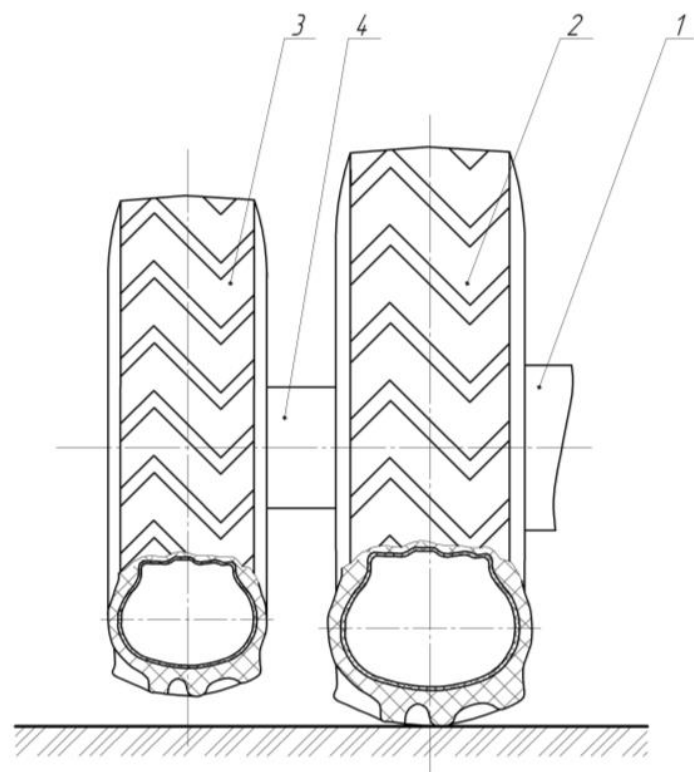

1 -wheel hub; 2 - primary pneumatic-tire wheel; 3 - additional pneumatic-tire wheel of a smaller diameter; 4 - coupling disc

Fig. 1. Wheeled automotive equipment with an additional wheel of a smaller diameter during movement over solid bearing surface

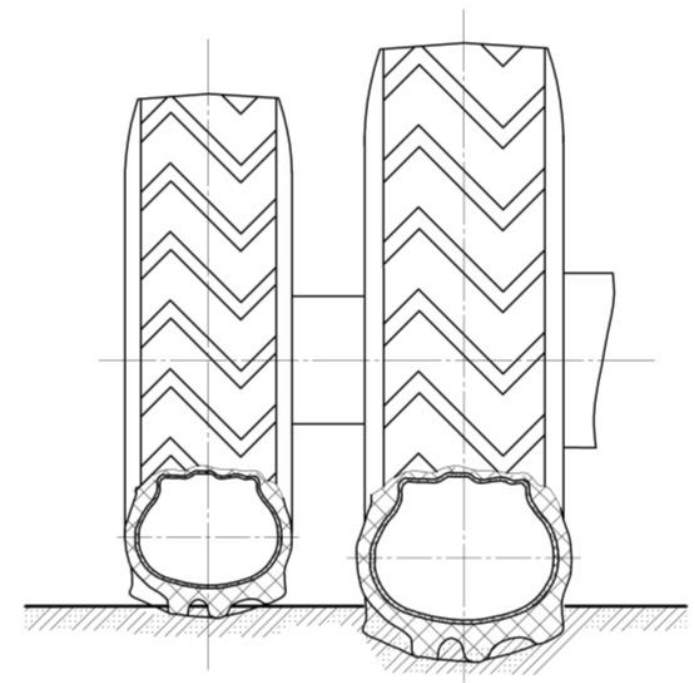

Fig. 2. Wheeled automotive equipment with an additional wheel of a smaller diameter during movement over deforming bearing surface 
It is known that operation of earth-moving machines includes traction and transport modes. Application of this design of automotive equipment will enhance work efficiency on weak soils and in case of digging-in during increased wheel slipping in traction mode. During transport operations on solid soils and asphalt concrete (high speed and low slipping), additional wheels are not engaged and do not increase resistance to motion and cornering.

\section{Experimental studies}

Experimental studies of tractive and fuel-consumption properties were carried out on the wheeled tractor T-150K (Fig. 3), used as a tractive vehicle for towing and attachable earthmoving equipment.

Additional wheels of a smaller diameters were installed on the rear axle of the tractor, and the front driving axle was disabled. Tractor braking was carried out by a special dynamometric brake system [9].

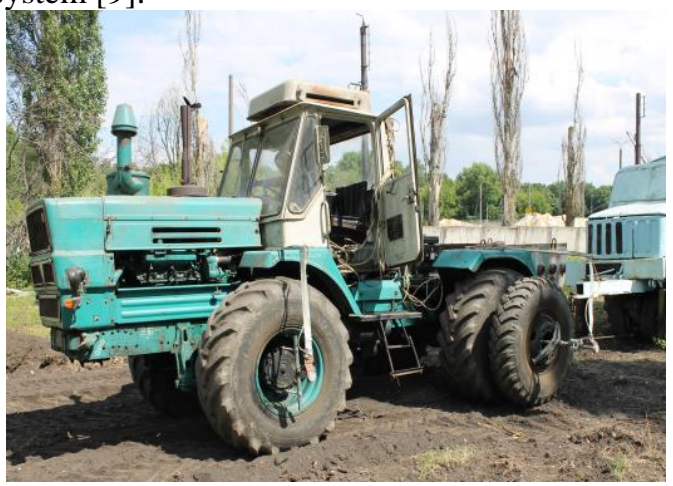

Fig. 3. Tractor $\mathrm{T}-150 \mathrm{~K}$ with additional wheels of a smaller diameter on the rear axle

Changes of tractive properties were assessed both with and without additional wheels (standard wheels with tires 21.3-24P model ФД-14A, outside diameter 1,400 mm; additional wheels 14.00-20 model I-307, outside diameter 1,220 mm).

The following parameters were registered during the study: rotation speed of tractor's wheels (driving rear and driven (when disabled) front wheels) and the fifth when, drawbar tractive effort and fuel consumption rate. Tractive effort was measured with a tension meter (Fig. 4), calibrated on the universal four-column hydraulic test system INSTRON Satec 1500HDX in the Yu. M. Borisov's Common Use Center of the Voronezh State Engineering University.

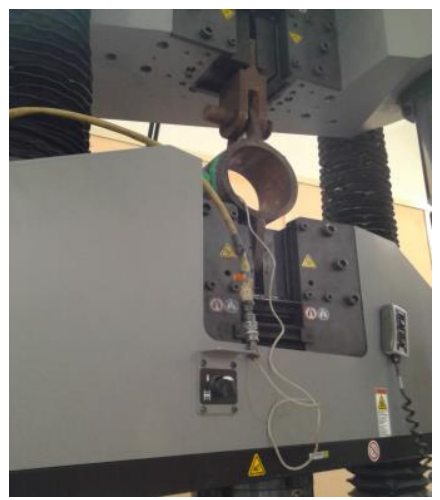

Fig. 4. Tension meter calibration process 
To measure the hourly fuel consumption of the tractor's the diesel engine fuel volume flow meter IP 179 PS was installed in the engine supply system. Measured parameters were recorded by a set of mobile digital equipment, designed for experimental studies of dynamic processes in earth-moving machines, consisting of a sensor system, input module L-CARD E14-140, a switching unit with independent power supply and an energyindependent notebook with a SSD hard drive [10].

The following bearing surfaces were used: frim soil (12..14 impacts of a DORNII ram tester, bulk humidity $11,3 \ldots 12,7 \%)$, loose soil (3...5 impacts, bulk humidity $15,5 \ldots 16,0 \%)$, sand (1..2 impacts, bulk humidity $9,8 \ldots 12,3 \%)$.

All surfaces were prepared by stripping the top soil followed by surface levelling.

\section{Analysis of dependences}

According to curves in Fig. 5, traction performance of a tractive vehicle with additional wheels on firm soil is practically the same as that of a vehicle without additional wheels. Tractive power $N_{\max }$, tractive efficiency $\eta_{\max }$ and specific traction fuel consumption $g_{\text {Tmax }}$ of a tractive vehicle with and without additional wheels are equal. Only the maximum tractive creepage $T_{\max }$ is $4,7 \%$ higher.

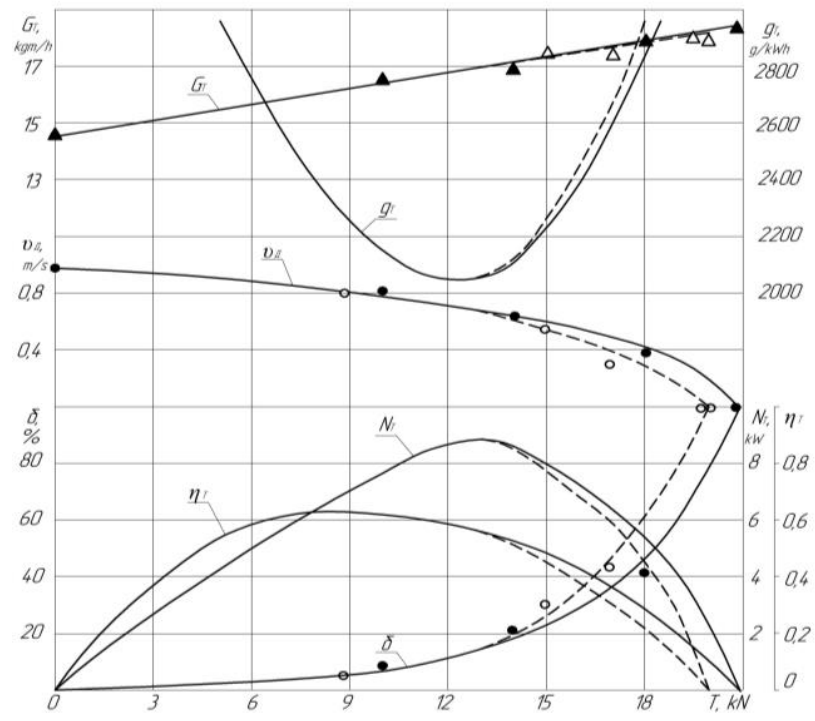

Fig. 5. Experimental tractive characteristic on firm soil without additional wheels (index 1) and with additional wheels (index 2)

The obtained results show that additional wheels of a smaller diameter start contacting the ground only during wheel slipping $\delta$ of about $20 \%$ and tractive power $T \approx 13 \mathrm{kN}$, and as the tractive power grows, the contact area of the smaller wheels increases, resulting in increased traction creepage of the driving machine in general.

According to curves in Fig.6, additional wheels of a smaller diameter on loose soil come in contact with the ground at wheel slipping $\delta=2,5 \%$ or at tractive power $T=6 \mathrm{kN}$, therefore all parameters of the traction characteristic are higher than when additional wheels are not used.

The maximum tractive creepage $T_{\max }$ is $7,7 \%$ higher, the maximum tractive power $N_{\max }$ is $14 \%$ higher, the maximum traction efficiency $\eta_{\max }$ is $3,5 \%$ higher, and the minimum specific fuel consumption $g_{\text {тmax }}$ is $13 \%$ lower. 


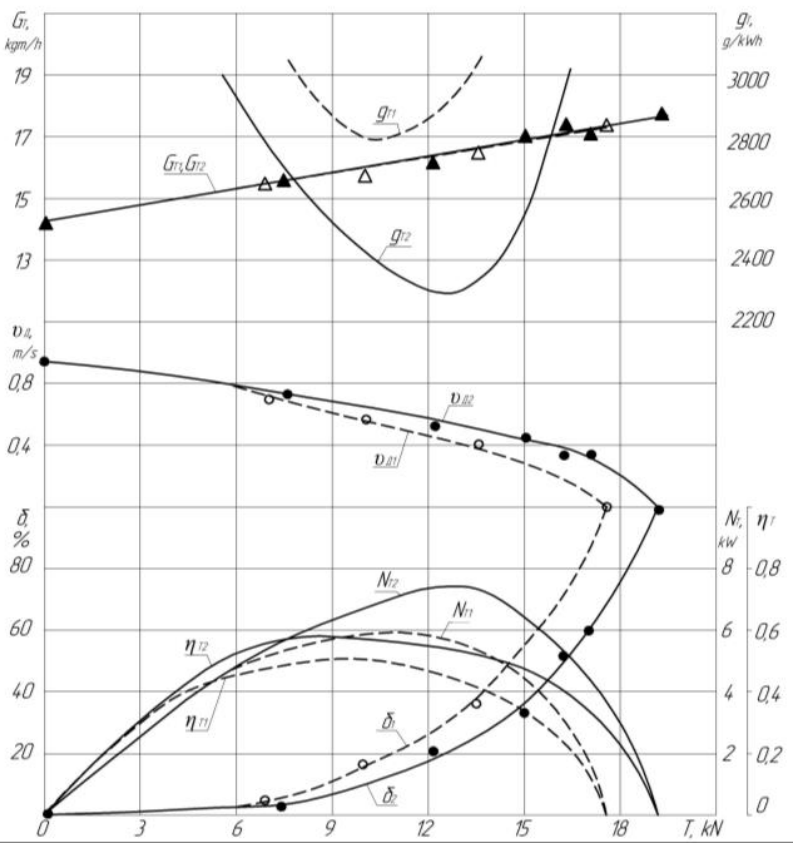

Fig. 6. Experimental tractive characteristic of a tractive vehicle on loose soil without additional wheels (index 1) and with additional wheels (index 2)

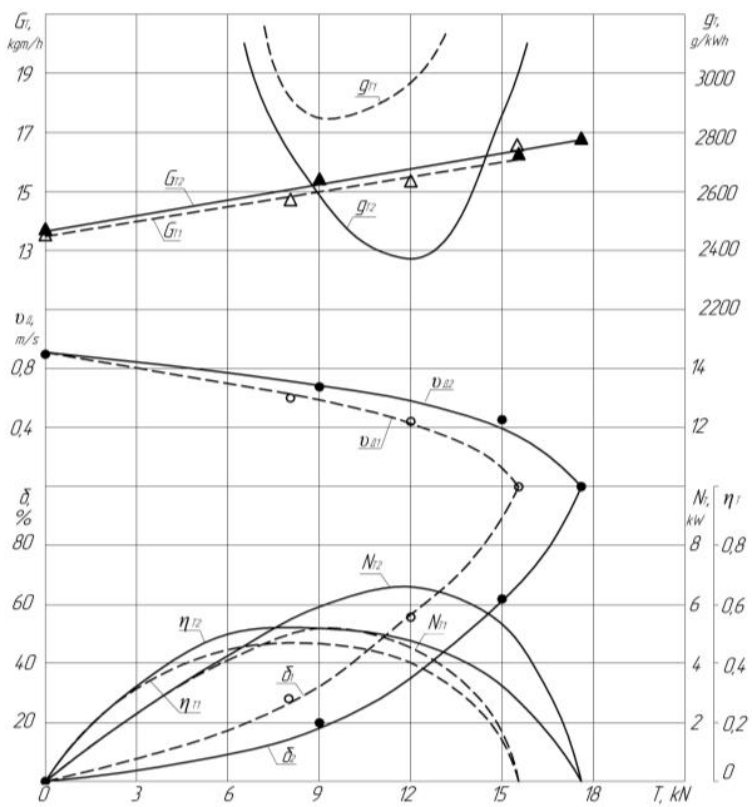

Fig. 7. Experimental tractive characteristic of a tractive vehicle on sand without additional wheels (index 1) and with additional wheels (index 2)

According to curves in Fig. 7, the similar pattern is observed as for sand conditions, where additional wheels come in contact with the ground immediately $(\delta=0, T=0)$. Parameters of the traction characteristic of a tractive vehicle with additional wheels are 
higher than that without additional wheels: $T_{\max }$ is $13 \%$ higher, $N_{\max }$ is $25 \%$ higher, $\eta_{\max }$ is $9.4 \%$ higher, $g_{\text {Tmax }}$ is $21 \%$ lower.

\section{Conclusions}

The performed experimental studies show that the use of additional wheels of a smaller diameter on driving axles of earth-moving machines results in increased tractive characteristics on any soil surfaces, to a lesser extent on firm soil and to a higher degree on loose soils.

The use of doubled wheels enables accommodation of higher vertical loads, for example, in case of additional loading of rear wheels, when a pull-type scarper is used.

It should be noted that doubled wheels improve controllability in case of off-center loading of a working attachment on wheeled earth-moving machines.

The obtained results require further experimental and theoretical studies.

\section{References}

1. A. I. Dotsenko, G. N. Karasyov, G. V. Kustaryov, K. K. Shestopalov Earthwork machines: student's textbook - M.: BASTET Publishing House. (2012)

2. G. N. Frolova Study of road-hold properties of tractor MT3-82 with doubled wheels during non-linear motion in Far East conditions. Abstract of a thesis for candidate degree in engineering sciences. - Blagoveshchensk. (2004)

3. N. A. Kuznetsov Improvement of utilization efficiency of machines with tractor PT-M160 by enhancing its tractive properties. Abstract of a thesis for candidate degree in engineering sciences. - Chelyabinsk. (2007)

4. A. V. Anrdianov Improvement of technical and economic characteristics of a wheeled tractor by enhancing its running gear during spring field works (based on XT3-150K-09). Thesis for candidate degree in engineering sciences. - Chelyabinsk. (2015)

5. Pat. 2265526 Russian Federation, МПК В 60 B 15/26, В 60 B 15/08. Wheeled running gear [Text] / I. M. Kurochkin, S. S. Chelnokov; applicant and patent holder Tambov State Engineering University (TSEU) - No. 2008119895/11; appl. 23.06.03; published on 10/12/05, Bull. No. 32 (P. II.)

6. Pat. 2220052 Russian Federation, МПК В 60 B 15/26. Auxiliary disc for improved passing ability of a vehicle [Text] / A. V. Pichugin; applicant and patent holder A V. Pichugin. - № 2002118096/20; appl. 16.07.02; published on 27.12.03, Bull. No. 3 (P. II)

7. Pat. 2511240 Russian Federation, МПК В 60 B 15/26. Driving wheel of a vehicle [Text] / Yu. I. Yakimov; applicant and patent holder Federal State Budgetary Higher Vocational Educational Institution Kuban State Agricultural University No. 2012132931/11; appl. 01.08.12; published on 10.04.14, Bull. No. 10 (P. II)

8. Pat. 2449896 Russian Federation, МПК В 60 В 15/26, В 60 В 15/22, В 60 В 15/08, В 60 C 27/20, B 60 C 27/04, B 60 C 27/02. Anti-wheelspin gear [Text] / V. V. Chernichenko, S. V. Chernichenko, V. V. Chernichenko; applicant and patent holder Vladimir Viktorovich Chernichenko - No. 2011103498/11; appl. 02.02.11; published on 10.05.12, Bull. No. 13 (P. II)

9. N. A. Ulyanov, L. Kh. Sharipov Brake unit for traction testing of earth-moving machines /. In: Studies and calculations of construction and road-building machines. 2. Voronezh, VSU Publishing House. (1975)

10. V. A. Zhulay, V. Vasilenko, V. L. Tyunin, A. V. Krestnikov. Constr. Mech. 8 (2015) 